\title{
The Effect of Customers' Emotional Responses to Service Failures on Their Recovery Effort Evaluations and Satisfaction Judgments
}

\author{
Amy K. Smith \\ George Washington University
}

Ruth N. Bolton

University of Oklahoma

This study examines the role of customer emotions in the context of service failure and recovery encounters. It investigates how customers' emotional responses to service failures influence their satisfaction judgments after accounting for cognitive antecedents of satisfaction. The study also considers how customers' emotional responses to service failures influence how they evaluate an organization's recovery efforts. The research is conducted by surveying customers about their satisfaction judgments in two service settings, restaurants and hotels. The results suggest that customers' emotional responses to service failures will influence their recovery effort evaluations and satisfaction judgments in some circumstances and that the effects of emotion vary across industry settings. This study identifies the types of efforts that are most effective in helping customers "recover" from the negative emotions caused by service failures.

Service failure and recovery encounters represent critical moments of truth for organizations in their efforts to satisfy and keep customers. These encounters may also be pivotal moments for customers, many of whom experience strong emotional reactions in response to service failures and subsequently decide whether to continue their

Journal of the Academy of Marketing Science.

Volume 30, No. 1, pages 5-23.

Copyright $(\mathcal{O} 2002$ by Academy of Marketing Science. relationship with the organization. Research by Berry and Parasuraman (1991) and Zeithaml, Berry, and Parasuraman (1993) supports the notion that customers are more emotionally involved in, and more observant of, recovery service than routine or first-time service. While some researchers have begun to investigate the impact of customers' affective state on their service evaluations (Andreassen 2000; Dubé and Maute 1996; Hui and Tse 1996; Taylor 1994) and on satisfaction processes (Mano and Oliver 1993; Oliver 1993; Westbrook and Oliver 1991; Wirtz and Bateson 1999), no empirical studies have specifically addressed how customers' emotional responses to service failures influence their evaluations of various types of recovery efforts and their satisfaction with the service encounter.

This gap in the current services marketing literature is somewhat surprising given that consumer behavior research has shown that individuals use different informationprocessing strategies depending on their emotional state (e.g., Bless, Bohner, Schwarz, and Strack 1990; Isen 1987; Mackie and Worth 1989; Schwarz and Bless 1991). These studies suggest that both the amount and type of information processing that customers engage in during a service encounter will vary based on their emotional responses and will consequently influence their evaluations. Therefore, it also seems likely that customers' satisfaction will be influenced by their emotional responses to service failures and that they may respond differently to various types of recovery efforts (e.g., compensation, apology, etc.) depending on their emotional state. 
FIGURE 1

Effects of Customers' Emotional Responses to Service Failures on Their Recovery Effort Evaluations and Satisfaction Judgments

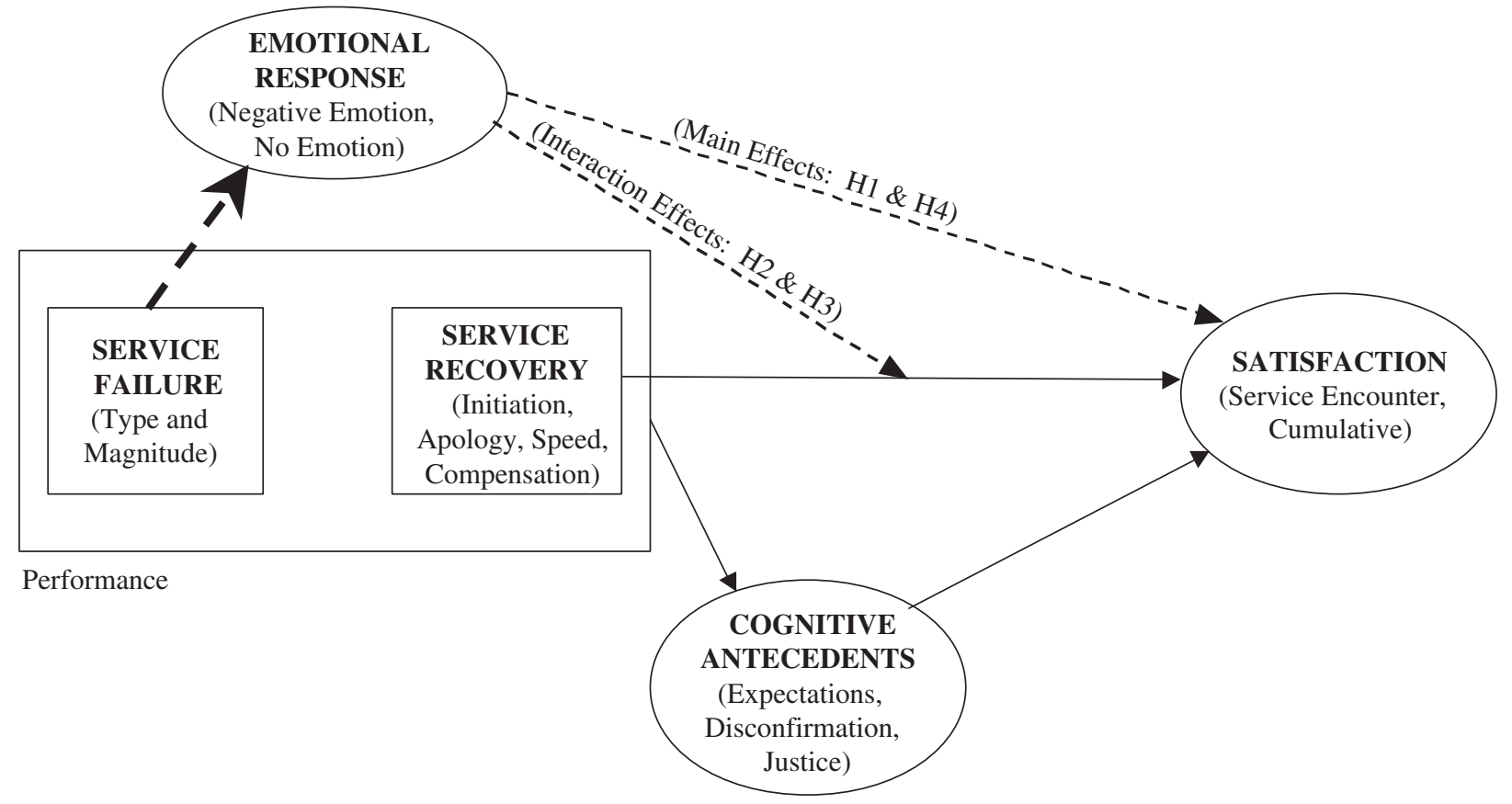

NOTE: Arrows with broken pattern denote the relationships that are the focus of this study. Arrows with solid pattern denote relationships established in prior research. Emotional responses are triggered by the service failure as denoted by the bold arrow and are measured after the service failure but prior to service recovery. Service failure performance has been shown in prior research to affect satisfaction (arrow not shown). Tests are conducted to determine whether interaction effects involve pure or quasi-moderation.

This study examines the role of customer emotions in the context of service failure and recovery encounters. It investigates the following research questions:

- Do customers' emotional responses to service failures influence their service encounter satisfaction?

- If so, how? That is, do emotional responses operate directly or indirectly? Are they pure or quasi-moderators?

- Do customers' emotional responses to service failures influence how they process and "weigh" the organization's recovery efforts?

- Do customers' emotional responses to service failures also influence their overall (cumulative) satisfaction judgments?

In this study, we develop and estimate a statistical model of the effects of emotion on service encounter satisfaction after accounting for cognitive antecedents of satisfaction (e.g., performance, disconfirmation, and justice). The results provide insights regarding the role of emotions in customer satisfaction with service failure and recovery. They also provide guidance to managers about how organizations can effectively recover from the negative emotions caused by service failures. The following section reviews the relevant literature and provides a conceptual framework for the study. Next, we describe the research design. Then, we develop a statistical model of how customers' emotional responses to service failures influence their evaluations of the organization's recovery efforts and their satisfaction with the service encounter. Finally, we discuss the study results and outline the managerial implications and directions for future research.

\section{REVIEW AND CONCEPTUAL FRAMEWORK}

This section describes a framework for examining the role of emotion in customers' satisfaction with service failure and recovery encounters and develops a set of testable hypotheses. The conceptual framework includes both cognitive and emotional antecedents to customers' satisfaction with service failure and recovery encounters, as illustrated in Figure 1. We make a general prediction (Proposition 1) that emotion will influence the formation of customers' transaction-specific satisfaction judgments. Then, we develop four hypotheses. The first two hypotheses predict how emotion will influence service encounter (i.e., transaction-specific) satisfaction-that is, either directly (via a main effect) and/or indirectly (via interaction effects with cognitive antecedents). The third 
hypothesis describes how emotion will moderate the effects of the organization's service recovery effort. The fourth hypothesis concerns the influence of emotion on customers' overall (i.e., cumulative) satisfaction judgments.

\section{Cognitive Antecedents to Satisfaction}

In the classic expectancy disconfirmation model, customer satisfaction with consumption experiences depends on expectations, performance, and disconfirmation (Churchill and Surprenant 1982; Oliver 1980; Oliver and DeSarbo 1988). Social exchange theorists have identified three dimensions of perceived justice (fairness) that may also influence how customers evaluate consumption experiences: distributive justice, which involves resource allocation and the perceived outcome of exchange (Adams 1965; Deutsch 1975); procedural justice, which involves the means by which decisions are made and conflicts are resolved (Leventhal 1980; Lind and Tyler 1988; Thibaut and Walker 1975); and interactional justice, which involves the manner in which information is exchanged and outcomes are communicated (Bies and Moag 1986: Bies and Shapiro 1987).

While Oliver and Swan (1989a, 1989b) considered the joint influence of disconfirmation and perceived justice on customer satisfaction, they only addressed one aspect of perceived justice, namely, the distributive (equity) aspect. Recently, researchers have begun to examine the influence of all three types of perceived justice on customer satisfaction and behavioral intentions after service failure and recovery encounters (e.g., Blodgett, Hill, and Tax 1997; Tax, Brown, and Chandrashekaran 1998). Smith, Bolton, and Wagner (1999) considered the complementary influences of disconfirmation and perceived justice on customer satisfaction. They found that in service failure and recovery encounters, disconfirmation complements perceived justice in the prediction of satisfaction with service failure and recovery encounters, but it is the lesser of the two determinants.

\section{Emotional Antecedents to Satisfaction}

Consistent with previous research by Mano and Oliver (1993), Oliver (1993), and Westbrook (1987), Wirtz and Bateson (1999) have suggested that satisfaction is a partly cognitive and partly affective (emotional) evaluation of a consumption experience and that separating cognitive antecedents from emotional antecedents is both valuable and necessary for modeling consumer behavior in service settings. Oliver (1997) has stated that emotion "coexists alongside various cognitive judgments in producing satisfaction" (p. 319) and that it is central to understanding customers' consumption experiences. Although there seems to be no generally agreed-upon definition among marketing scholars, Bagozzi, Gopinath, and Nyer (1999) have recently defined emotions as mental states of readiness that arise from cognitive appraisals of events or one's own thoughts. Bagozzi et al. (1999) suggested that emotions typically have a specific referent (e.g., a customer is angered by inattentive service in a restaurant). Consistent with Cohen and Areni (1991), they considered affect to be a general category for mental feeling processes that includes emotions, moods, and (possibly) attitudes. Oliver (1997) further pointed out that emotion tends to be more cognitively involved than affect (p. 294). Bagozzi et al. (1999) distinguished emotions from moods in that moods tend to be lower in intensity than emotions, are generally nonintentional, do not have a specific referent, and are not as directly coupled with action tendencies as are emotions.

In this study, we investigate the influence of emotions arising from a specific referent, that is, a service failure. Service failures often evoke strong emotional responses from customers. Prior research has shown that consumers' affective response to service failures (e.g., emotions of being irritated, angry, annoyed, etc.) will influence their service evaluations (Dubé and Maute 1996; Folkes, Koletsky, and Graham 1987; Hui and Tse 1996; Taylor 1994). Bagozzi et al. (1999) have observed that emotions often function in broad categories or "amalgamated groupings" of positive and negative emotion/affect (p. 200). This study investigates the emotions provoked by service failures (which are undesirable), so it focuses on amalgamated groupings of negative emotions. Andreassen (1999) found that initial negative emotion triggered by a service failure had a negative impact on customers' satisfaction with the organization's complaint resolution efforts and stimulated exit behavior. Therefore, we believe that customers' transaction-specific satisfaction-that is, their satisfaction with the specific service failure and recovery effort-will be influenced by their emotions after accounting for the effects of cognitive antecedents.

Proposition 1: Customers' emotional responses to service failures will significantly influence their (postrecovery) service encounter satisfaction, after accounting for the effects of cognitive antecedents.

This proposition is a very general prediction that emotion influences service encounter satisfaction directly (via a main effect) or indirectly (via interaction effects) or both, after accounting for cognitive antecedents. In the empirical portion of this study, we will compare the service encounter satisfaction formation process for respondents who did not experience emotional responses after failure versus respondents who did experience them and test whether the two subgroups can be pooled. In the remainder of this section, we develop three specific hypotheses about the mechanism by which emotion influences customers' service encounter satisfaction. Hypotheses 1 and 2 make separate predictions about direct (main) and indirect 
(interaction) effects of emotion on service encounter satisfaction. Hypothesis 3 predicts that customers who experience emotional responses after service failure will evaluate the organization's overall recovery effort differently than customers who do not experience emotional responses.

\section{Emotion and Evaluations}

Individuals who are in a positive emotional state have been shown to evaluate products more positively than individuals in neutral or negative emotional states (Isen, Shalker, Clark, and Karp 1978; Srull 1983, 1984). This finding indicates that customers who experience a strong (negative) emotional response to service failures are likely to view a service failure/recovery encounter less favorably than customers who are in a more positive (i.e., less negative or neutral) emotional state. Therefore, we predict that negative emotions (provoked by service failures) will have a negative main effect on service encounter satisfaction.

Hypothesis 1: Customers who respond to service failures with more (negative) emotion will be less satisfied with a service failure/recovery encounter than customers who respond with less (or no) emotion, ceteris paribus.

Social psychology researchers also suggest that affective states have a stronger influence on evaluations when the judgments require a higher degree of constructive (online) processing (Fiedler 1990; Forgas 1994, 1995). This notion suggests that the evaluations of customers experiencing emotion (i.e., customers who are likely to be engaging in more detailed, systematic, and complex judgment processes) would differ from those customers experiencing no emotion. Thus, we predict that negative emotions (provoked by service failures) will interact with cognitive antecedents (i.e., performance, disconfirmation, perceived justice) to influence service encounter satisfaction.

Hypothesis 2: In their evaluations of service failure/recovery encounters, customers who respond to service failures with more (negative) emotion will weigh the cognitive antecedents of service encounter satisfaction differently than customers who respond with less (or no) emotion.

\section{Emotion and Information Processing}

According to Bagozzi et al. (1999), “a person's emotional state can influence various aspects of information processing including encoding and retrieval of information, different strategies used to process information, evaluations and judgments, and creative thinking" (p. 195). Prior research has shown that individuals who are in a positive emotional state process less information and tend to use top-down processing strategies, simple heuristics, and holistic judgments with little attention to detail or logical consistency, whereas individuals who are in a negative emotional state process more information and tend to use bottom-up strategies, specific (rather than abstract) reasoning, and more elaborate and detailed analytic processes (Bless et al. 1990, 1996; Mackie and Worth 1989; Schwarz and Bless 1991). Hereafter, we follow convention and use the term systematic to refer to this latter processing strategy.

Bagozzi et al. (1999) suggested that this difference may be attributed to the fact that positive affect indicates a "benign environment" that does not require any action (p. 198). Therefore, individuals in a positive emotional state are not motivated to engage in systematic processing and use more simplistic processing and heuristics instead. On the other hand, negative affect represents a problematic environment; therefore, individuals in a negative emotional state are motivated to engage in systematic processing, which is better suited to problem solving and handling "threatening" situations (Schwarz 1990; Schwarz and Clore 1983).

Customers who experience a service failure are likely to be in emotional states ranging from neutral to extremely negative. Therefore, our study includes customers who experience higher versus lower levels of (negative) emotion with the most positive emotional state being represented by the lowest level of emotion (i.e., no emotion or a neutral emotional state). Extrapolating from the aforementioned research, we expect that customers who experience a strong (negative) emotional response to a service failure will evaluate the organization's overall recovery effort more systematically in forming their satisfaction judgments than customers who experience little or no emotion. Hence, we predict that the satisfaction judgments of customers who experience a strong (negative) emotional response to a service failure will be more heavily influenced by recovery performance and other cognitive antecedents (i.e., disconfirmation and perceived justice) than the satisfaction judgments of customers who experience little or no emotion.

Hypothesis 3: Recovery performance and other cognitive antecedents will account for more explained variance in the satisfaction judgments of customers who respond to service failures with emotion than in the satisfaction judgments of customers who respond with less (or no) emotion.

\section{Emotion and Cumulative Satisfaction}

There is growing evidence that as a customer gains more confidence or experience over time in assessing a 
service, he or she weighs his or her prior assessments of services more heavily and places less weight on new information (e.g., Bolton 1998; Boulding, Kalra, and Staelin 1995; Tax et al. 1998). In other words, prior assessments carry over, and new information is relatively less influential. Hence, it seems likely that customers' cumulative satisfaction with the service organization will be less influenced by emotion than their transaction-specific satisfaction. Although this study focuses on the antecedents of transaction-specific satisfaction, rather than overall satisfaction, it is useful to conduct a preliminary exploration of how emotion influences cumulative satisfaction. Thus, we propose the following:

Hypothesis 4: Customers' emotional responses will explain more variance in customers' transactionspecific satisfaction than in their overall (cumulative) satisfaction.

\section{A Conceptual Model of the Effects of Emotion on Customer Satisfaction}

Based on our review of the relevant research, we expect that customer satisfaction with service failure and recovery encounters will depend on cognitive antecedents including expectation, performance, disconfirmation, and three types of perceived justice-distributive, procedural, and interactional justice. In addition to these cognitive antecedents, we also expect customer satisfaction with service failure and recovery encounters to depend on emotion. These concepts can be expressed algebraically as follows:

SESat $=f($ Expectations, Performance,

Disconfirmation, Distributive Justice,

Procedural Justice, Interactional Justice, Emotion),

where SESat denotes service encounter satisfaction after recovery efforts.

Proposition 1 predicts that customers' emotional responses to service failures will significantly influence their (postrecovery) service encounter satisfaction, after accounting for cognitive antecedents. The most general way to state this proposition, assuming a linear additive functional form, is to form two equations-one equation to characterize the evaluations of customers who respond with (negative) emotion and another equation to characterize the responses of customers who respond with no emotion. Algebraically,

$$
\begin{aligned}
& \text { SESat }_{E}=\text { Intercept }_{E}+a_{E} \text { Expectations }+b_{E} \text { Performance } \\
& +c_{E} \text { Disconfirmation }+d_{E} \text { Distributive Justice } \\
& +e_{E} \text { Procedural Justice }+f_{E} \text { Interactional Justice } \\
& +\varepsilon_{E}
\end{aligned}
$$
ative) emotional response to service failures and $N$ denotes customers who have no emotional response. The main ef fect of emotion is captured by the difference between the intercepts of the two equations. The interaction effects of emotion are represented by the different coefficients in Equations 2 and 3. Note that by writing separate equations for the two subgroups (rather than writing one large equation with many interaction effects), we have allowed the error $(\varepsilon)$ variances of the two equations to be different. The operationalization and estimation of the model described by Equations 2 and 3 is described in detail later in the article.

Hypothesis 1 predicts that customers who respond to service failures with emotion will tend to be less satisfied after recovery. Algebraically, we predict that the intercept of Equation 2 will be smaller than the intercept of Equation 3, that is, Intercept ${ }_{E}<$ Intercept $_{N}$. Hypothesis 2 predicts that customers who respond to service failures with emotion will respond differently than customers who have no emotional response, that is, the vector of coefficients in Equation 2 will not be equal to the vector of coefficients in Equation 3. Algebraically, the null hypothesis for Hypothesis 2 is that (jointly) $a_{E}=a_{N}, b_{E}=b_{N}, c_{E}=c_{N}, d_{E}=d_{N}, e_{E}=$ $e_{N}$, and $f_{E}=f_{N}$. We do not predict whether emotion acts as a pure or quasi-moderator variable. However, following our testing for a main effect (Hypothesis 1) and interaction effect (Hypothesis 2) of emotion, we test whether emotion is a pure or quasi-moderator variable. Hypothesis 3 predicts that recovery performance and other cognitive antecedents (i.e., disconfirmation and perceived justice) will account for more explained variance in the service encounter satisfaction judgments of customers who respond to service failures with emotion than in the satisfaction judgments of customers who respond with less (or no) emotion. We investigate this hypothesis by comparing the relative explanatory power of the coefficients of the relevant variables in the two equations. Last, we test Hypothesis 4 with a rudimentary analysis of how emotion influences cumulative satisfaction (relative to transaction-specific satisfaction) after controlling for cognitive antecedents.

It is important to note that while customers' evaluations of service failure and recovery encounters may be influenced by their general emotional state (i.e., positive, neutral, or negative), it is also possible that customers' evaluations would vary by the type and level (intensity) of discrete emotions (such as anger, disappointment, anxiety, etc.) that underlie their overall affective condition. Some researchers suggest that appraisal theories may be useful 
in explaining these discrete emotional responses (e.g., Frijda 1986; Lazarus 1991; Roseman 1991). We explore the possibility of modeling discrete emotional responses in the empirical portion of our article.

\section{RESEARCH DESIGN}

This study was conducted in two different service settings_-restaurants and hotels. Prior research suggests that for services high in experience or credence properties, customers may rely on their affective reactions to derive satisfaction judgments (Alford and Sherrell 1996). Hospitality services are high in experience qualities, and service failures in this industry are common. However, customer reactions to service failures in credence services (e.g., financial, legal, medical services) may be even more emotion laden. Therefore, hospitality services provide a very appropriate study context but a more "conservative" test of the effect of emotion on customer satisfaction with service failure and recovery encounters.

\section{Sampling Frame and Experimental Design}

The samples for the study were composed of customers who had recently patronized a particular restaurant or hotel. In the restaurant study, 355 undergraduate students were surveyed in groups of 20 to 40 using self-report questionnaires. (Students may have somewhat different attribute importance weights than other restaurant customer segments, but we believe that this feature does not make them less appropriate for this study than any other customer group.) To ensure that study participants had prior experience with the restaurant being evaluated, they were asked to name a specific restaurant (other than a fast-food restaurant) they had visited in the past 3 months. In the hotel study, a probability sample of business traveler customers was selected from a midrange hotel chain's general reservation list of customers who had stayed at one of their locations within the previous 3 months. A mail survey offered respondents a cash incentive for completing and returning the questionnaire, and obtained a response rate of 30 percent-yielding surveys from 549 hotel customers. An advantage of studying two hospitality service industries with somewhat different data collection methods is that we combine high external validity in the restaurant study with high internal validity in the hotel study. In other words, the results of the restaurant study can be generalized across multiple organizations within the same industry, whereas the results of the hotel study control for extraneous differences due to heterogeneity across organizations within the same industry. For this reason, we believe that our results may also generalize to other types of services.
Experimentally generated scenarios were used to allow for the systematic investigation of a more representative and inclusive set of failure/recovery encounters than is possible with retrospective survey approaches. Specifically, our study was designed to generate a variety of common service failure scenarios that would provoke emotional responses and, subsequently, to provide combinations of typical recovery efforts for customers to evaluate. Two failure attributes, type of failure (outcome or process) and magnitude of failure (high or low), were manipulated to create variability in customers' emotional responses. ${ }^{1}$ (Since this manipulation might create covariation between failure attributes and customer emotions, failure attributes were controlled for in the statistical analyses.) Several researchers have classified service failures along outcome or process dimensions to examine customer responses (Bitner, Booms, and Tetreault 1990; Hoffman, Kelley, and Rotalsky 1995; Keaveney 1995). Outcome failures relate to the core service offering, while process failures relate to the manner in which the service is delivered (e.g., failures that are directly attributed to the actions of service personnel). Many researchers have also examined and demonstrated the effects of magnitude of the failure, seriousness of the complaint, or severity of the dissatisfaction problem on customer responses (e.g., Bearden and Oliver 1985; Gilly and Gelb 1982; Hoffman et al. 1995; Maute and Forrester 1993; Richins 1987).

It is important to note that, consistent with Shiv and Fedorikhin (1999), the focus of this study is on stimulusinduced emotion (i.e., affect that arises from a stimulus, which in this case is a service failure manipulation) rather than task-induced emotion (i.e., affect that arises directly from the structure or difficulty of the decision task itself ) or ambient emotion (affect that arises from background conditions such as fatigue or mood) (Isen 1997; Yates 1990). In our experimental design, we create failure-provoked emotions and then control for other variables to investigate the effects of emotion on service recovery evaluations and satisfaction rather than manipulating emotion orthogonal to other treatments so that respondents would be randomly assigned to emotion groups. The latter procedure is not desirable since it would create exogenous emotions that are independent of the failure condition.

The design also included manipulations of four service recovery attributes: compensation (high, medium, or none), response speed (immediate or delayed), apology (present or absent), and recovery initiation (prompted by the service employee or prompted by the customer). These attributes were chosen because they (1) are prominent in the popular business press, (2) have received some empirical support in the academic literature (e.g., Berry and Parasuraman 1991; Clemmer and Schneider 1993; Goodwin and Ross 1992; Tax et al. 1998), (3) are particularly salient to customers, (4) can be acted upon by 
managers, and (5) can be manipulated via written scenarios in an experimental context.

These manipulations allowed for an investigation into how customers' emotional responses to service failures may influence their assessment of an organization's recovery efforts. Customers were randomly exposed to 1 of 96 different service failure and recovery combinations (4 failures $\times 24$ recoveries) that were created using a between-subjects design. Examples of the service failure scenarios and recovery attributes for both restaurants and hotels are provided in Smith et al. (1999).

\section{Task and Questionnaire}

The questionnaire used for both studies began by asking participants to name a restaurant or a hotel location (within the hotel chain) that they had visited within the past 3 months. They then answered a series of open-ended questions regarding their prior experience with the organization (e.g., time of last visit, frequency of visits) followed by a short battery of structured questions regarding their loyalty to, and cumulative satisfaction with, the organization. Then, customers were asked to engage in a role-playing exercise in which they imagined a return visit to the particular restaurant or hotel they had patronized and read a hypothetical (experimentally generated) scenario describing a service failure and a recovery effort that occurred there. In the questionnaire, the service failure and recovery scenario was presented in two stages. First, customers read a description of the service failure scenario. Immediately afterward, they wrote down their thoughts and feelings about the failure encounter (i.e., a retrospective verbal protocol). Then, they answered a short battery of structured questions to determine their evaluations of the failure encounter (including a manipulation check for magnitude of the failure, attribution measures, and propensity to complain/exit measures). Second, customers read a recovery scenario that described the restaurant or hotel's response (in terms of the four recovery attributes) to the service failure they "experienced." Finally, they answered questions regarding their evaluations of the service encounter and their cumulative satisfaction with, and repatronage intentions toward, the hotel or restaurant. To summarize, the respondents' task sequence was as follows:

Service Failure Scenario Manipulation

$\downarrow$

Emotion Measurement (Verbal Protocol)

$\downarrow$

Service Recovery Scenario Manipulation

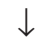

Service Encounter Evaluation and Satisfaction Measurement (Structured Questions)

\section{Measures of Emotions and Expectations}

The service failure manipulations are designed to provoke negative emotions. ${ }^{2}$ Emotional responses to the service failure were captured by eliciting verbal protocols from customers after the administration of a failure scenario. Expectations about recovery attributes were captured in the same way. On average, customers generated about three complete thoughts (i.e., sentences) in their written response to the service failure scenario. These thoughts included both cognitive and emotional content. Customers' expectations and their emotional responses to the service failure were measured by conducting a content analysis (Collins and Kalton 1980; Morton-Williams and Young 1987) of their open-ended responses to the following instruction: "In the space below, briefly write down any thoughts or feelings that you have about the problem described."

Verbal protocols (as opposed to direct measures) were used to avoid eliciting expectations and emotions that otherwise might not have been operating in customers' evaluations. Also, Weber (1985) argued that a content analysis of responses to open-ended questions yields more unobtrusive measures than the analysis of close-ended survey questions (i.e., with fixed alternative responses) because the act of measurement does not confound the data. Measuring emotion via content analysis of verbal protocols is a technique that has been successfully used by other researchers (e.g., Fiebig and Kramer 1998). Furthermore, Richins (1997) has recently demonstrated that many commonly used direct measures of emotion (e.g., scales developed by Batra and Holbrook 1990; Edell and Burke 1987; Izard 1977; Mehrabian and Russell 1974; Plutchik 1980) are unsuited for the purpose of measuring consumptionrelated emotions.

The content analysis indicated that the majority (95\%) of customers' responses did not contain any mention of expectations regarding service recovery. This result indicates that in general, customers' expectations about recovery are relatively passive, ambiguous, and ill defined and that expectations operate only indirectly (via disconfirmation) to influence satisfaction. In contrast, customers' verbal protocols frequently contained emotional responses (e.g., "I feel disappointed because they [the restaurant] did not have the item I wanted"; "I am very frustrated and annoyed that a [hotel] guest with my record of frequent stays would not have been accommodated"; "I am angry that he [the waiter] did not check up on our service"). On the basis of Oliver's (1997:312) categorization of negative emotion labels and Richins's (1997) Consumption Emotion Set (CES), we grouped customers' (negative) emotions words into five categories and then 
TABLE 1

Emotions Coding Categories

\begin{tabular}{|c|c|c|c|c|c|}
\hline Emotion & Anger & Discontent & Disappointment & Self-Pity & Anxiety \\
\hline Coding categories & $\begin{array}{l}\text { Angry } \\
\text { Mad } \\
\text { Outraged } \\
\text { Enraged } \\
\text { Furious } \\
\text { Infuriated } \\
\text { Irate } \\
\text { Ticked } \\
\text { Pissed } \\
\text { Ballistic } \\
\text { Hostile } \\
\text { Vengeful } \\
\text { Blaming } \\
\text { Sarcastic }\end{array}$ & $\begin{array}{l}\text { Discouraged } \\
\text { Distressed } \\
\text { Disturbed } \\
\text { Dismayed } \\
\text { Impatient } \\
\text { Agitated } \\
\text { Irritated } \\
\text { Perturbed } \\
\text { Annoyed } \\
\text { Aggravated } \\
\text { Frustrated } \\
\text { Exasperated } \\
\text { Fed up } \\
\text { Cranky } \\
\text { Upset } \\
\text { Unpleasant } \\
\text { Unhappy } \\
\text { Bad } \\
\text { Disgruntled } \\
\text { Displeased } \\
\text { Dissatisfied } \\
\text { Disgusted }\end{array}$ & $\begin{array}{l}\text { Surprised } \\
\text { Astounded } \\
\text { Shocked } \\
\text { Disappointed } \\
\text { Unimpressed } \\
\text { Underwhelmed }\end{array}$ & $\begin{array}{l}\text { Inconvenienced } \\
\text { Put out } \\
\text { Ripped off } \\
\text { Unappreciated } \\
\text { Unimportant } \\
\text { Unwanted } \\
\text { Neglected } \\
\text { Ignored } \\
\text { Uncomfortable } \\
\text { Tired } \\
\text { Embarrassed } \\
\text { Ashamed } \\
\text { Rebuffed } \\
\text { Mistreated } \\
\text { Offended } \\
\text { Insulted } \\
\text { Betrayed } \\
\text { Disregarded } \\
\text { Discriminated against }\end{array}$ & $\begin{array}{l}\text { Confused } \\
\text { Anxious } \\
\text { Bothered } \\
\text { Concerned }\end{array}$ \\
\hline Restaurant incidence $^{a}$ & $10.4 \%$ & $34.4 \%$ & $19.4 \%$ & $5.4 \%$ & $2.3 \%$ \\
\hline Hotel incidence $^{\mathrm{a}}$ & $5.5 \%$ & $30.6 \%$ & $5.3 \%$ & $3.8 \%$ & $2.2 \%$ \\
\hline
\end{tabular}

a. Expressed as a percentage of respondents expressing at least one thought. Each row sums to equal the percentage of customers with emotional responses. Since virtually all (97\%) of respondents expressed at least one thought (with or without emotional content), these percentages are roughly equivalent to the percentage of respondents.

counted the occurrence of words falling into each category. The five (negative) emotions coding categories were anger, discontent, disappointment, self-pity, and anxiety as described in Table $1 .^{3}$

A possible criticism of the use of hypothetical failure scenarios may be that it is difficult to stimulate the level of emotional involvement generated by an actual service failure/recovery encounter. However, the content analysis of customers' verbal protocols seemed to reveal a relatively high degree of emotional involvement, as indicated by respondents' frequent use of affective descriptors such as irritated, upset, mad, furious, mistreated, and fed up. Furthermore, debriefing of respondents after think-aloud interviews and conventional pretests of the questionnaire indicated that the scenarios were emotionally involving to them. We believe that the scenarios were emotionally involving because (1) respondents were actual customers with real experiences with the organizations they were evaluating, and (2) manipulation checks revealed that the respondents found them to be very realistic. This degree of ecological validity was attained through careful development of the scenarios through reviews of company service and complaint records, interviews with managers and frontline service personnel, think-aloud interviews with customers, and extensive pretesting of the failure/recovery manipulations. The significant effects of emotion found in this study under conditions of lower involvement (i.e., using written scenarios) offer strong support for the ecological validity of the results.

We created an objective measure of the presence and/or absence of negative emotions in the following way. We began by creating dummy variables for the presence and/or absence of emotional content in each of the five (negative) emotion coding categories and for the presence and/or absence of overall emotional content (in any of the five negative emotion categories). Preliminary analyses and statistical tests indicated that it would not be possible to separately model the effects of different emotions (i.e., anger, discontent, disappointment, self-pity, anxiety) because the sample sizes for the different emotion categories are too small.

\section{Measures of Performance, Disconfirmation, Perceived Justice, and Satisfaction}

Performance is represented by seven indicator (zero/one) variables for the service failure and recovery attribute manipulations-type and magnitude of failure and nature of the recovery effort (initiation, apology, speed, and two levels of compensation). Service encounter 
satisfaction after recovery efforts (SESat), disconfirmation, distributive justice, procedural justice, and interactional justice were measured using scales adapted from previous studies. These scales and their measurement properties are described in detail in Smith et al. (1999). Cumulative satisfaction was measured on the same 7-point scale as service encounter satisfaction except that it asked respondents to make a judgment about their overall satisfaction with the organization rather than their transaction-specific satisfaction.

\section{MODEL OPERATIONALIZATION AND ESTIMATION}

Based on our conceptual framework represented in Figure 1 and summarized by Equations 2 and 3, we now operationalize a statistical model of how customers' emotional responses to service failures influence their evaluations of the organization's recovery efforts and their satisfaction with the service encounter.

\section{Model Operationalization}

To operationalize Equations 2 and 3, we used the dummy variable for the presence and/or absence of overall emotional content to divide restaurant and hotel customers into two groups. Customers were considered to have a (negative) emotional response if they recorded one or more emotional thoughts (i.e., thoughts containing one or more of the emotion coding words included in Table 1). Customers were considered to have no emotional response if they did not record any emotional thoughts (i.e., were in a neutral emotional state). Intensity of emotion (i.e., arousal level) was also coded based on the respondent's use of descriptive adverbs in conjunction with emotion words (e.g., very angry, extremely annoyed, a little disappointed). However, this additional information did not have any effect on the explanatory power or the results of the model and, therefore, was omitted from the analysis.

Note that a customer may have had emotional thoughts but did not record them. We used presence or absence of emotion to divide the groups into emotion versus no-emotion groups because this criterion can be objectively defined from a coding standpoint, while any other criterion would be subjective. This grouping criterion also resulted in relatively equal-sized groups ( 426 customers and 478 in the emotion versus no-emotion groups), which is desirable for analysis and model estimation. By grouping customers in this way, it is possible to estimate equations for four data subsets, that is, two services (restaurant and hotel) and two levels of emotional responses (emotion and no emotion).

This approach allows us to assess the interaction effects of customers' emotional responses to service failures on their encounter satisfaction after an organization's recov- ery effort by comparing the coefficient estimates of customers with emotion versus no emotion. Algebraically,

$$
\begin{aligned}
\text { SESat }_{R} & =\text { Intercept }+b_{1 R} \text { Type (Outcome) } \\
& +b_{2 R} \text { Magnitude (High) }+b_{3 R} \text { Initiation }+b_{4 R} \text { Apology } \\
& +b_{5 R} \text { Speed }+b_{6 R} \text { Compensation (Medium) } \\
& +b_{7 R} \text { Compensation (High) }+c_{R} \text { Disconfirmation } \\
& +d_{R} \text { Distributive Justice }+e_{R} \text { Procedural Justice } \\
& +f_{R} \text { Interactional Justice }+\varepsilon_{R},
\end{aligned}
$$

where $R$ denotes the emotion $(E)$ or no-emotion $(N)$ groups. The cognitive antecedents of disconfirmation and perceived justice are measured by single items or indices as described earlier, and performance is represented by indicator variables for service failure type and magnitude, as well as for the service recovery attributes (initiation, apology, speed, and compensation). These indicator variables take on the value 1 when the attribute is present and 0 otherwise. Note that due to the virtual absence of (and lack of variability in) customers' expectations (as revealed by the content analysis), the main effect of expectations shown in Equations 1, 2, and 3 was not included in the operationalization of the model represented by Equation 4 .

\section{Model Estimation Procedure}

To account for individual differences in customers' emotional states, a set of covariates-including propensity to voice, propensity to exit, and age-was included in the estimation of Equation 4 for each of the four data subsets. These variables were included because they have been shown to be related to customers' evaluations and behaviors (e.g., Richins 1983; Singh 1990) and because they were found to be statistically significant covariates in the model equation for one or more of the four data subsets. Other variables suggested by researchers as having a potential influence on evaluations and behaviors, such as attributions (e.g., Bitner 1990; Blodgett, Granbois, and Walters 1993; Sparks and Callan 1996; Tax and Chandrashekaran 1992) and gender (e.g., Dubé and Morgan 1996), were not included in the model because these variables were either controlled for in the research design (e.g., locus and controllability attributions) and/or they were not statistically significant covariates in the equation. Number of thoughts was also tested as a possible covariate to account for individual differences between customers based on amounts of verbosity in their responses, but it was not included in the model because it was not statistically significant in the equation.

We estimate Equation 4 in its most general form, with separate equations for the emotion and no-emotion groups. In doing so, we allow for emotion to (potentially) have a main effect and an interaction effect-plus we allow the variances of the error terms in the emotion and no-emotion equations to be different. As a first step, we 
TABLE 2 Descriptive Statistics

\begin{tabular}{|c|c|c|c|c|c|c|}
\hline \multirow[b]{2}{*}{$\underline{\text { Variable }}$} & \multicolumn{2}{|c|}{$\begin{array}{l}\text { Restaurants } \\
\mathrm{N}=355\end{array}$} & \multicolumn{2}{|c|}{$\begin{array}{l}\text { Hotels } \\
\mathrm{N}=549\end{array}$} & \multicolumn{2}{|c|}{$\begin{array}{l}\text { Combined Industry Sample Data } \\
\qquad \mathrm{N}=904\end{array}$} \\
\hline & Emotion & No Emotion & Emotion & No Emotion & Emotion & No Emotion \\
\hline Incidence in study & $\begin{array}{c}59 \% \\
(n=208)\end{array}$ & $\begin{array}{c}41 \% \\
(n=147)\end{array}$ & $\begin{array}{l}40 \% \\
(n=218)\end{array}$ & $\begin{array}{c}60 \% \\
(n=331)\end{array}$ & $\begin{array}{l}47 \% \\
(n=426)\end{array}$ & $\begin{array}{c}53 \% \\
(n=478)\end{array}$ \\
\hline Number of thoughts & 3.09 & 2.87 & $3.20 * * *$ & 2.40 & $3.15^{* * * *}$ & 2.54 \\
\hline$R^{2}$ for service encounter satisfaction & .67 & .72 & .83 & .85 & .74 & .84 \\
\hline$R^{2}$ for overall (cumulative) satisfaction & .38 & .53 & .35 & .84 & .32 & .80 \\
\hline
\end{tabular}

NOTE: Results for $t$-test comparisons on number of thoughts for customers with an emotional response versus customers with no emotional response are shown in the emotion column. $R^{2}$ statistics are the result of estimating Equation 4 for each group using the dependent variable specified. $* * * p<.01$.

use Glesjer's (1969) test to check whether the error variances of the two equations are indeed different. We find that they are the same for the restaurant setting, but different for the hotel $(p<.01)$. This result confirms that we must estimate separate equations for the hotel data so that the standard assumption of regression, namely, that $\mathrm{E}(\varepsilon N \mid$ $\mathrm{X})=0$, is true.

Glesjer's (1969) test also indicated that there was heteroscedasticity in the error terms for the restaurant model due to different numbers of thoughts generated across customers (Greene 1993; Johnston 1972). Further evidence of heterogeneity across customer groups was demonstrated by differences in number of thoughts between emotion versus no-emotion groups, as shown in Table 2. Hence, we corrected for heteroscedasticity by estimating all equations with weighted least squares (WLS) with the inverse of number of thoughts used as the weighting factor. Respondents generated between 0 and 12 thoughts. The average number of thoughts across all respondents was 3.2. When a customer recorded no (0) thoughts, we replaced 0 with 0.01 for the purposes of WLS estimation. This replacement was necessary for a total of 32 respondents across both settings, or 3.5 percent of all respondents.

\section{RESULTS AND DISCUSSION}

We performed $F$ tests to determine if the data should be combined (i.e., pooled) by service setting (i.e., to determine that the vectors of coefficients for the restaurant and hotel data are equal). The calculated $F$ statistics were $F=$ 1.79 for the high-emotion group and $F=1.75$ for the low-emotion group. At $\alpha=.05$, the test suggests that combining the two industry subsamples is not appropriate because the $F$ statistics we obtained are slightly greater than the critical value of 1.67. At $\alpha=.01$, the test suggests that pooling across settings is appropriate because the $F$ statistics obtained are less than the critical $F$ value of 2.04. This result suggests that the differences in coefficient estimates are statistically significant $(p<.05)$ but that the differences in effect sizes are generally small. Therefore, in our investigation of Hypotheses 1 and 2, we examine both the individual industry subsample results and the combined industry sample results. We do this for two reasons. (1) By examining the results from the industry subsamples, we can explore whether some results may vary by service setting. (2) When the effect sizes for the influences of emotion are small, combining the two industry subsamples may allow us to find effects that would not be detectable in smaller samples. Since it is possible that the combined industry sample results may be misleading due to heterogeneity across the two industry subsamples (c.f., Jedidi, Jagpal, and DeSarbo 1997), the pooled (by industry) results should be interpreted with caution.

All results are from WLS estimation. The overall fit of the model was good. The adjusted $R^{2}$ values for the service encounter satisfaction equation for customers with (negative) emotion were .64 for restaurants and .82 for hotels ( $p<.0001$ for both). The adjusted $R^{2}$ values for the service encounter satisfaction equation for customers with no emotion were .69 for restaurants and .85 for hotels ( $p<$ .0001 for both). The results for restaurants are shown in Table 3, the results for hotels are shown in Table 4, and the results for the combined industry sample data are shown in Table 5. Statistical test results_-including tests of Proposition 1, Hypothesis 1, Hypothesis 2, Hypothesis 3, and Hypothesis 4-are summarized in Table 6.

Customers' emotional responses to service failures significantly influence their (postrecovery) service encounter satisfaction. We begin by investigating Proposition 1 , that is, testing whether there are differences in satisfaction judgment formation between emotion and no-emotion groups after controlling for cognitive antecedents. We tested this proposition by conducting a Chow (1960) test, that is, an $F$ test or pooling test in which the full model for service encounter satisfaction (i.e., separate equations for the emotion and no-emotion groups) is compared with a reduced model (i.e., a single equation for the pooled data) (see Neter and Wasserman 1974:88). As shown in Table 6, an $F$ test does not reject the hypothesis that the emotion and no-emotion groups can be pooled for the restaurant data $(F=1.39, p>.10)$. However, $F$ tests reject the hypoth- 
TABLE 3

Weighted Least Squares ResultsRestaurant Study

\begin{tabular}{|c|c|c|c|}
\hline Variable & Emotion $^{\mathrm{a}}$ & No Emotion ${ }^{\mathrm{a}}$ & Pooled $^{\mathrm{b}}$ \\
\hline Intercept & $\begin{array}{c}1.30 \\
(0.80)\end{array}$ & $\begin{array}{c}0.36 \\
(1.20)\end{array}$ & $\begin{array}{c}1.02 \\
(0.66)\end{array}$ \\
\hline \multicolumn{4}{|l|}{ Failure performance } \\
\hline Failure type (outcome) & $\begin{array}{c}0.08 \\
(0.23)\end{array}$ & $\begin{array}{c}0.01 \\
(0.33)\end{array}$ & $\begin{array}{l}-0.10 \\
(0.18)\end{array}$ \\
\hline Failure magnitude (high) & $\begin{array}{l}-0.13 \\
(0.27)\end{array}$ & $\begin{array}{l}-0.01 \\
(0.27)\end{array}$ & $\begin{array}{c}0.03 \\
(0.17)\end{array}$ \\
\hline Type $\times$ Magnitude & $\begin{array}{c}0.00 \\
(0.33)\end{array}$ & $\begin{array}{l}-0.95^{* *} \\
(0.44)\end{array}$ & $\begin{array}{l}-0.41 \\
(0.25)\end{array}$ \\
\hline \multicolumn{4}{|l|}{ Recovery performance } \\
\hline $\begin{array}{l}\text { Recovery initiation } \\
\text { (by organization) }\end{array}$ & $\begin{array}{c}0.18 \\
(0.17)\end{array}$ & $\begin{array}{c}0.18 \\
(0.22)\end{array}$ & $\begin{array}{r}0.22^{*} \\
(0.13)\end{array}$ \\
\hline Apology & $\begin{array}{l}0.35^{*} \\
(0.20)\end{array}$ & $\begin{array}{c}0.24 \\
(0.29)\end{array}$ & $\begin{array}{l}0.41^{* * * *} \\
(0.16)\end{array}$ \\
\hline Speed & $\begin{array}{c}0.19 \\
(0.16)\end{array}$ & $\begin{array}{c}0.29 \\
(0.22)\end{array}$ & $\begin{array}{c}0.17 \\
(0.13)\end{array}$ \\
\hline Compensation (medium) & $\begin{array}{r}0.35^{*} \\
(0.21)\end{array}$ & $\begin{array}{l}0.82 * * * \\
(0.29)\end{array}$ & $\begin{array}{l}0.55^{* * *} \\
(0.17)\end{array}$ \\
\hline Compensation (high) & $\begin{array}{l}0.65^{* * * *} \\
(0.24)\end{array}$ & $\begin{array}{l}0.67 * * \\
(0.32)\end{array}$ & $\begin{array}{l}0.62^{* * * *} \\
(0.18)\end{array}$ \\
\hline \multicolumn{4}{|l|}{ Cognitive antecedents } \\
\hline Disconfirmation & $\begin{array}{l}0.41 * * * \\
(0.07)\end{array}$ & $\begin{array}{l}0.26 * * * \\
(0.10)\end{array}$ & $\begin{array}{l}0.35^{* * * *} \\
(0.06)\end{array}$ \\
\hline Distributive justice & $\begin{array}{l}0.38^{* * * *} \\
(0.11)\end{array}$ & $\begin{array}{l}0.62 * * * \\
(0.14)\end{array}$ & $\begin{array}{l}0.50 * * * \\
(0.08)\end{array}$ \\
\hline Procedural justice & $\begin{array}{l}-0.10 \\
(0.12)\end{array}$ & $\begin{array}{l}-0.04 \\
(0.15)\end{array}$ & $\begin{array}{l}-0.10 \\
(0.09)\end{array}$ \\
\hline Interactional Justice & $\begin{array}{c}0.14 \\
(0.12)\end{array}$ & $\begin{array}{l}0.35^{* *} \\
(0.15)\end{array}$ & $\begin{array}{l}0.22 * * \\
(0.09)\end{array}$ \\
\hline \multicolumn{4}{|l|}{ Covariates } \\
\hline Propensity to complain & $\begin{array}{l}-0.17 * * * \\
(0.06)\end{array}$ & $\begin{array}{l}-0.11 \\
(0.07)\end{array}$ & $\begin{array}{l}-0.21 * * * \\
(0.04)\end{array}$ \\
\hline Propensity to exit & $\begin{array}{l}-0.12 * * \\
(0.05)\end{array}$ & $\begin{array}{l}-0.01 \\
(0.05)\end{array}$ & $\begin{array}{l}-0.04 \\
(0.03)\end{array}$ \\
\hline Age & $\begin{array}{l}-0.03 \\
(0.02)\end{array}$ & $\begin{array}{l}-0.06 * * \\
(0.03)\end{array}$ & $\begin{array}{l}-0.04 * * \\
(0.02)\end{array}$ \\
\hline $\begin{array}{l}R^{2} \\
\text { Adjusted } R^{2}\end{array}$ & $\begin{array}{l}.67 \\
(.64)\end{array}$ & $\begin{array}{l}.72 \\
(.69)\end{array}$ & $\begin{array}{l}.71 \\
(.70)\end{array}$ \\
\hline$F$ statistic & $24.99 * * *$ & $21.75 * * *$ & $54.66 * * *$ \\
\hline
\end{tabular}

a. Unstandardized coefficients are shown with standard errors in parentheses.

b. Since the results show that emotion has no effect on satisfaction judgments in the restaurant data, we estimate a single equation that combines the emotion and no-emotion groups.

$* p \leq .10 . * * p \leq .05 . * * * p \leq .01$.

esis that the emotion and no-emotion groups can be pooled for the hotel data $(F=1.65, p<.10)$ and the combined restaurant and hotel data $(F=4.56, p<.01)$. In other words, we reject the hypothesis that the coefficient vectors for the emotion versus no-emotion groups are equal in the hotel data and in the combined industry sample data, but not in the restaurant data. Thus, the results indicate that customers' emotional responses to service failures significantly contribute to the explained variance in their service encounter satisfaction judgments in the hotel and combined industry sample data, after accounting for the effects of
TABLE 4 Weighted Least Squares Results—Hotel Study

\begin{tabular}{|c|c|c|c|c|}
\hline Variable & Emotion $^{\mathrm{a}}$ & $\begin{array}{c}\text { No } \\
\text { Emotion }^{\mathrm{a}}\end{array}$ & $\begin{array}{l}\text { \% Explained } \\
\text { Variance } \\
\text { (Emotion })^{\mathrm{b}}\end{array}$ & $\begin{array}{c}\text { \% Explained } \\
\text { Variance } \\
(\text { No Emotion })^{\mathrm{b}}\end{array}$ \\
\hline Intercept & $\begin{array}{c}0.01 \\
(0.41)\end{array}$ & $\begin{array}{l}-0.01 \\
(0.37)\end{array}$ & & \\
\hline \multicolumn{5}{|c|}{ Failure performance } \\
\hline $\begin{array}{l}\text { Failure type } \\
\text { (outcome) }\end{array}$ & $\begin{array}{c}-0.04 \\
(0.18)\end{array}$ & $\begin{array}{l}0.30^{* *} \\
(0.14)\end{array}$ & 0.0 & 0.9 \\
\hline $\begin{array}{l}\text { Failure magni- } \\
\text { tude (high) }\end{array}$ & $\begin{array}{l}-0.01 \\
(0.19)\end{array}$ & $\begin{array}{l}0.46^{* * *} \\
(0.19)\end{array}$ & 0.0 & 2.6 \\
\hline $\begin{array}{l}\text { Type } \times \text { Magni- } \\
\text { tude }\end{array}$ & $\begin{array}{l}-0.20 \\
(0.25)\end{array}$ & $\begin{array}{l}-1.02 * * * \\
(0.25)\end{array}$ & 0.7 & 11.6 \\
\hline \multicolumn{5}{|c|}{ Recovery performance } \\
\hline $\begin{array}{l}\text { Recovery initi } \\
\text { ation (by } \\
\text { organization) }\end{array}$ & $\begin{array}{c}0.18 \\
(0.12)\end{array}$ & $\begin{array}{l}-0.63 * * * \\
(0.10)\end{array}$ & 0.6 & 4.7 \\
\hline Apology & $\begin{array}{l}-0.07 \\
(0.15)\end{array}$ & $\begin{array}{c}0.18 \\
(0.15)\end{array}$ & 0.1 & 0.4 \\
\hline Speed & $\begin{array}{c}0.25 \\
(0.18)\end{array}$ & $\begin{array}{l}-0.10 \\
(0.18)\end{array}$ & 1.1 & 0.1 \\
\hline $\begin{array}{l}\text { Compensation } \\
\text { (medium) }\end{array}$ & $\begin{array}{c}0.00 \\
(0.16)\end{array}$ & $\begin{array}{l}-0.11 \\
(0.14)\end{array}$ & 0.0 & 0.1 \\
\hline $\begin{array}{l}\text { Compensation } \\
\text { (high) }\end{array}$ & $\begin{array}{c}0.22 \\
(0.17)\end{array}$ & $\begin{array}{c}0.17 \\
(0.16)\end{array}$ & 0.7 & 0.4 \\
\hline \multicolumn{5}{|c|}{ Cognitive antecedents } \\
\hline Disconfirmation & $\begin{array}{l}0.26^{* * * *} \\
(0.06)\end{array}$ & $\begin{array}{c}0.00 \\
(0.05)\end{array}$ & 14.9 & 0.0 \\
\hline $\begin{array}{l}\text { Distributive } \\
\text { justice }\end{array}$ & $\begin{array}{l}0.55^{* * * *} \\
(0.06)\end{array}$ & $\begin{array}{l}0.14 * * * \\
(0.05)\end{array}$ & 75.6 & 3.6 \\
\hline $\begin{array}{l}\text { Procedural } \\
\text { justice }\end{array}$ & $\begin{array}{c}0.02 \\
(0.04)\end{array}$ & $\begin{array}{l}0.09 * * \\
(0.04)\end{array}$ & 0.1 & 2.3 \\
\hline $\begin{array}{l}\text { Interactional } \\
\text { justice }\end{array}$ & $\begin{array}{l}0.14 * * * \\
(0.06)\end{array}$ & $\begin{array}{l}0.58 * * * \\
(0.05)\end{array}$ & 4.8 & 62.4 \\
\hline \multicolumn{5}{|l|}{ Covariates } \\
\hline $\begin{array}{l}\text { Propensity to } \\
\text { complain }\end{array}$ & $\begin{array}{c}0.04 \\
(0.04)\end{array}$ & $\begin{array}{l}-0.24 * * * \\
(0.05)\end{array}$ & 0.3 & 4.1 \\
\hline $\begin{array}{l}\text { Propensity } \\
\text { to exit }\end{array}$ & $\begin{array}{l}-0.04 \\
(0.04)\end{array}$ & $\begin{array}{c}0.02 \\
(0.03)\end{array}$ & 0.4 & 0.0 \\
\hline Age & $\begin{array}{l}-0.01 * \\
(0.00)\end{array}$ & $\begin{array}{l}0.03 * * * \\
(0.00)\end{array}$ & 0.7 & 6.7 \\
\hline $\begin{array}{l}R^{2} \\
\text { Adjusted } R^{2} \\
F \text { statistic }\end{array}$ & $\begin{array}{c}.83 \\
(.82) \\
60.51 * * *\end{array}$ & $\begin{array}{c}.85 \\
(.85) \\
114.37 * * *\end{array}$ & & \\
\hline
\end{tabular}

a. Unstandardized coefficients are shown with standard errors in parentheses.

b. This column shows the variance explained by each predictor variable as a percentage of total explained variance. The total explained variance was calculated by squaring the standardized coefficients and summing them. The portion of explained variance attributable to a predictor variable is calculated by squaring its standardized coefficient. Values may not sum exactly to 100 percent due to rounding. This information is used in evaluating Hypothesis 3 .

$* p \leq .10 . * * p \leq .05$. *** $p \leq .01$.

cognitive antecedents such as performance, disconfirmation, and perceived justice. The remainder of this section describes the tests of our hypotheses about the nature of this influence of emotion.

Customers who respond to service failure with more (negative) emotion may be less satisfied. To test Hypothesis 1, we 


\begin{tabular}{|c|c|c|}
\hline \multicolumn{3}{|c|}{$\begin{array}{c}\text { TABLE } 5 \\
\text { Weighted Least Squares Results- } \\
\text { Combined Industry Sample }^{\mathrm{a}}\end{array}$} \\
\hline Variable & Emotion $^{\mathrm{b}}$ & No Emotion ${ }^{\mathrm{b}}$ \\
\hline Intercept & $\begin{array}{c}0.42 \\
(0.30)\end{array}$ & $\begin{array}{c}1.05 \\
(0.32)\end{array}$ \\
\hline Setting (hotel) & $\begin{array}{l}0.36^{* *} \\
(0.17)\end{array}$ & $\begin{array}{l}-1.19 * * * \\
(0.21)\end{array}$ \\
\hline \multicolumn{3}{|l|}{ Failure performance } \\
\hline Failure type (outcome) & $\begin{array}{c}0.05 \\
(0.14)\end{array}$ & $\begin{array}{l}0.25 * * \\
(0.12)\end{array}$ \\
\hline Failure magnitude (high) & $\begin{array}{c}-0.12 \\
(0.16)\end{array}$ & $\begin{array}{l}0.51 * * * \\
(0.16)\end{array}$ \\
\hline Type $\times$ Magnitude & $\begin{array}{l}-0.06 \\
(0.20)\end{array}$ & $\begin{array}{l}-1.02 * * * \\
(0.21)\end{array}$ \\
\hline \multicolumn{3}{|l|}{ Recovery performance } \\
\hline Recovery initiation (by organization) & $\begin{array}{l}0.20 * * \\
(0.10)\end{array}$ & $\begin{array}{l}-0.59 * * * \\
(0.08)\end{array}$ \\
\hline Apology & $\begin{array}{l}0.22 * \\
(0.12)\end{array}$ & $\begin{array}{c}0.22^{*} \\
(0.12)\end{array}$ \\
\hline Speed & $\begin{array}{l}0.26^{* *} \\
(0.11)\end{array}$ & $\begin{array}{l}-0.05 \\
(0.14)\end{array}$ \\
\hline Compensation (medium) & $\begin{array}{c}0.19 \\
(0.13)\end{array}$ & $\begin{array}{l}-0.03 \\
(0.11)\end{array}$ \\
\hline Compensation (high) & $\begin{array}{l}0.45^{\text {**** }} \\
(0.14)\end{array}$ & $\begin{array}{c}0.17 \\
(0.14)\end{array}$ \\
\hline \multicolumn{3}{|l|}{ Cognitive antecedents } \\
\hline Disconfirmation & $\begin{array}{l}0.39 \text { *** } \\
(0.04)\end{array}$ & $\begin{array}{c}0.03 \\
(0.04)\end{array}$ \\
\hline Distributive justice & $\begin{array}{l}0.44^{* * *} \\
(0.05)\end{array}$ & $\begin{array}{l}0.16^{* * * *} \\
(0.04)\end{array}$ \\
\hline Procedural justice & $\begin{array}{c}-0.01 \\
(0.04)\end{array}$ & $\begin{array}{l}0.07 * * \\
(0.03)\end{array}$ \\
\hline Interactional justice & $\begin{array}{c}0.08 \\
(0.05)\end{array}$ & $\begin{array}{l}0.54 * * * \\
(0.04)\end{array}$ \\
\hline \multicolumn{3}{|l|}{ Covariates } \\
\hline Propensity to complain & $\begin{array}{c}-0.09 * * \\
(0.04)\end{array}$ & $\begin{array}{l}-0.25 * * * \\
(0.04)\end{array}$ \\
\hline Propensity to exit & $\begin{array}{l}-0.08^{* * * *} \\
(0.03)\end{array}$ & $\begin{array}{c}0.03 \\
(0.02)\end{array}$ \\
\hline Age & $\begin{array}{c}-0.01^{*} \\
(0.01)\end{array}$ & $\begin{array}{l}0.03^{* * * *} \\
(0.00)\end{array}$ \\
\hline $\begin{array}{l}R^{2} \\
\text { Adjusted } R^{2}\end{array}$ & $\begin{array}{c}.74 \\
(.73)\end{array}$ & $\begin{array}{c}.84 \\
(.84)\end{array}$ \\
\hline$F$ statistic & $67.84 * * *$ & $146.13^{* * *}$ \\
\hline
\end{tabular}

a. As discussed in the text, the combined industry sample results should be interpreted with caution.

b. Unstandardized coefficients are shown with standard errors in parentheses.

$* p \leq .10 . * * p \leq .05 . * * * p \leq .01$.

examine whether the intercepts of the equations for the emotion versus no-emotion groups are equal. In the hotel and restaurant data, the equation intercepts do not differ $(p>.10)$, whereas in the combined industry sample data set, the equation intercepts differ $(p<.05)$. See Table 6 . Specifically, in the combined industry sample data set, the equation intercept is lower for customers who have an emotional response (see Table 5). The difference in satisfaction ratings in the combined industry sample data is $(0.42-1.05)=-0.63$, that is, a little more than one half of a rating point on a 7-point scale. Thus, only the combined industry sample data support Hypothesis's 1 prediction that (negative) emotional responses by customers are related to lower levels of service encounter satisfaction after controlling for cognitive antecedents that might covary with emotional content. Since this effect is not significant in the industry subsamples, these results suggest that the direct (main) effect size of emotion on service encounter satisfaction is either nonexistent (i.e., an artifact of heterogeneity across the subsamples) or very small. Therefore, we now turn to the examination of indirect (interaction) effects of emotion on customers' evaluations.

In the hotel setting, customers who respond with more emotion to service failures weigh the cognitive antecedents of satisfaction differently than customers who respond with less emotion. In examining Tables 3,4 , and 5, we observe that the coefficients of the cognitive antecedents are different for the emotion versus no-emotion subgroups. We test Hypothesis 2 with an $F$ test of whether the coefficient estimates of the cognitive antecedents of service encounter satisfaction (i.e., performance, disconfirmation, perceived justice) are different for the two groups. The $F$ statistic for the restaurant data was not significant ( $p>$ .10). However, the pattern of results reveals that emotion interacts with the cognitive antecedents to influence customers' service encounter satisfaction in the hotel data $(p<.01)$ and the combined industry sample data $(p<.01)$.

Emotion is a pure moderator in the hotel subsample and a quasi-moderator in the combined industry sample data. Our hypotheses did not include a prediction on whether emotion functions as a pure or quasimoderator variable. However, our tests for main and interaction effects of emotion (Hypotheses 1 and 2) have yielded differing results across the industry subsamples and the combined industry sample results. Hence, we tested whether emotion is a "pure" moderator (i.e., the main effect of emotion on service encounter is not significant in the presence of interaction terms) or a "quasi-moderator" (i.e., the main effect and the interaction effects are significant). We investigated this issue using moderated regression analysis (Baron and Kenny 1986; Irwin and McClelland 2001; Sharma, Durand, and Gur-Arie 1981). Consistent with our results for Hypotheses 1 and 2, the test results indicated that emotion is not a moderator in the restaurant sample, a pure moderator in the hotel sample, and a quasi-moderator in the combined industry sample $(p<$ .05). ${ }^{4}$ See Table 6.

In summary, the moderator variable tests and tests of Proposition 1, Hypothesis 1, and Hypothesis 2 consistently show that emotion has no effect in the restaurant data, whereas emotion acts as a pure moderator in the hotel data. There are (at least) two reasons for this finding. First, the restaurant survey elicited satisfaction judgments for a recent visit to any restaurant (that does not serve fast food), 
TABLE 6

Summary of Statistical Tests

\begin{tabular}{|c|c|c|c|}
\hline Description of Test & Restaurant Data & Hotel Data & Combined Industry Sample Data \\
\hline \multicolumn{4}{|l|}{ Standard errors of emotion/no emotion } \\
\hline $\begin{array}{l}\text { Equations are equal } \\
\text { Glesjer's (1969) test }\end{array}$ & $\begin{array}{l}\text { Standard errors are equal } \\
(p>.10)\end{array}$ & $\begin{array}{l}\text { Standard errors are not equal } \\
(p<.01)\end{array}$ & $\begin{array}{l}\text { Standard errors are not equal } \\
(p<.01)\end{array}$ \\
\hline $\begin{array}{l}\text { Proposition 1: Effect of emotion after } \\
\text { accounting for effects of cognitive antecedents }\end{array}$ & $\begin{array}{l}\text { Pool } \\
\text { (No effect of emotion) }\end{array}$ & $\begin{array}{l}\text { Do not pool } \\
\text { (Effect of emotion) }\end{array}$ & $\begin{array}{l}\text { Do not pool } \\
\text { (Effect of emotion) }\end{array}$ \\
\hline Chow (1960) test of whether & $F=1.39$ & $F=1.65$ & $F=4.56$ \\
\hline $\begin{array}{l}\text { Equations } 2 \text { and } 3 \text { can be pooled } \\
\text { by emotion }\end{array}$ & $(p>.10)$ & $(p<.10)$ & $(p<.01)$ \\
\hline \multicolumn{4}{|l|}{ Hypothesis 1: Main effect of emotion } \\
\hline $\begin{array}{l}F \text { test of whether Intercept } \\
\text { across Equations } 2 \text { and } 3\end{array}$ & $\begin{array}{l}\text { No main effect } \\
(p>.10)\end{array}$ & $\begin{array}{l}\text { No main effect } \\
(p>.10)\end{array}$ & $\begin{array}{l}\text { Main effect } \\
(p<.05)\end{array}$ \\
\hline \multicolumn{4}{|l|}{ Hypothesis 2: Interaction effect of emotion } \\
\hline $\begin{array}{l}F \text { test of whether the coefficient vectors } \\
\text { (excluding the intercept) in Equations } 2 \\
\text { and } 3 \text { are equal; that is, joint test of } \\
a_{E}=a_{N}, b_{E}=b_{N}, c_{E}=c_{N}, d_{E}=d_{N} \\
\text { and } f_{E}=f_{N}\end{array}$ & $\begin{array}{l}\text { No interaction effect } \\
(p>.10)\end{array}$ & $\begin{array}{l}\text { Interaction effect } \\
(p<.01)\end{array}$ & $\begin{array}{l}\text { Interaction effect } \\
(p<.01)\end{array}$ \\
\hline $\begin{array}{l}\text { Quasi-moderator versus pure moderator } \\
\text { effect of emotion } \\
\text { Test as described by Baron and Kenny (1986) }\end{array}$ & Not a moderator & Pure moderator & Quasi-moderator \\
\hline $\begin{array}{l}\text { Hypothesis } 3 \text { : Comparison of explained } \\
\text { variance of recovery performance and } \\
\text { other cognitive antecedents } \\
\text { Coefficients of recovery performance } \\
\text { and cognitive antecedents are } b_{3 R}, b_{4 R}, b_{5 R} \text {, } \\
b_{6 R}, b_{7 R}, c_{R}, d_{R}, e_{R} \text {, and } f_{R} \text { in Equation } 4\end{array}$ & NA & $\begin{array}{l}\text { More explained variance } \\
\text { in emotion equation } \\
98 \%>74 \% \\
(p<.01)\end{array}$ & NA \\
\hline $\begin{array}{l}\text { Hypothesis 4: Comparison of the total } \\
\text { amount of explained variance accounted for } \\
\text { by emotion for transaction-specific versus } \\
\text { cumulative satisfaction } \\
\text { Percentage explained variance of emotion } \\
\text { variables (main and interaction effects) for } \\
\text { SESat > percentage explained variance of } \\
\text { emotion variables for OVRSat }\end{array}$ & NA & $\begin{array}{l}\text { More explained variance } \\
\text { for SESat than for OVRSat } \\
8.6 \%>6.6 \%\end{array}$ & NA \\
\hline
\end{tabular}

NOTE: NA = not applicable; SESat = service encounter satisfaction after recovery efforts; OVRSat = overall (cumulative) satisfaction with the service encounter. Since emotion is not a moderator variable in the restaurant setting, we do not test Hypotheses 3 and 4 in the restaurant setting. Furthermore, recall that we estimate the combined industry sample model—with its larger sample size — to check whether there is a (very small) main effect due to emotion (Hypothesis 1). Since the combined restaurant and hotel data must be interpreted with caution, we do not rely on the combined industry sample equations to test Hypotheses 3 and 4.

whereas the hotel survey elicited satisfaction judgments for a recent visit to a particular hotel chain. This design feature introduces variability into the restaurant data, as evidenced by the lower $R^{2}$. Second, the effect sizes of emotion may vary substantially across industries, that is, small for restaurants and (relatively) large for hotels.

Since the results consistently show that emotion has no effect on satisfaction judgments in the restaurant data, we estimate a single equation that combines emotion and noemotion groups. This equation is shown in Table 3. Since emotion has an effect on satisfaction judgments in the hotel data, the equations shown in Table 4 are the correct (final) equations. The primary reason for examining the combined industry sample data was to look for a potentially small main effect of emotion on transaction-specific satisfaction. Having done so, we do not analyze the combined industry sample data further. Instead, we test Hypotheses 3 and 4 by focusing on the hotel data, in which emotion has been shown to act as a pure moderator.

In the hotel setting, customers who respond with more emotion to service failures are more systematic in their evaluations of an organization's recovery performance. Since the restaurant data show no effects due to emotion, we test Hypothesis 3 in the hotel setting only. Table 4 shows the explanatory power of the variables in the emotion and no-emotion equations for hotels. Consistent with Hypothesis 3, hotel customers with (negative) emotion are processing the organization's recovery efforts more systematically. Specifically, recovery performance and the 
other cognitive antecedents (i.e., disconfirmation and perceived justice) of satisfaction account for 98 percent of the total variance explained in the emotion equation and 74 percent of the total variance explained in the noemotion equation, that is, the relative explanatory power of recovery performance and the other cognitive antecedents is 24 percent higher for the emotion group than for the no-emotion group. The difference in the sizes of the relevant coefficients is statistically significant $(p<.01)$.

A supplementary analysis of the verbal protocols also provides indirect support for the notion that customers who respond with emotion are "systematically" processing information. As shown in Table 2, 47 percent of all respondents recorded at least one emotional response to the service failure. Customers in the restaurant study were more likely to record at least one emotional response than customers in the hotel study (59\% vs. 40\%). Across both studies, respondents who recorded an emotional response generated significantly more thoughts than customers who did not record any emotional responses $(3.15>2.54, p<$ $.01)$. This finding suggests that emotional responses are associated with increased cognitive activity.

In summary, Hypothesis 3 is supported in two comparisons of emotion and no-emotion groups: explanatory power of recovery attributes and associated $F$ test for hotels, and comparisons with respect to number of thoughts for both restaurants and hotels. Thus, we conclude that customers who respond more emotionally to service failures seem to process information more systematically and thoroughly. Since we randomized the assignment of failure conditions to respondents and controlled for other relevant factors, this finding must be due to cognitive differences caused by varying levels of emotion between the groups. ${ }^{5}$ These findings are consistent with prior research studies that find that people with more negative emotions engage in more systematic processing and less heuristic processing than people with positive emotions.

Customers' emotional responses to service failures more strongly "color" their transaction-specific evaluations than their overall (cumulative) satisfaction judgments. Recall that since the restaurant data show no effects due to emotion, we test Hypothesis 4 in the hotel setting only. We did not develop a completely specified model for cumulative satisfaction. Hence, to test Hypothesis 4, we substituted overall (i.e., cumulative) satisfaction for service encounter (i.e., transaction-specific) satisfaction as the dependent variable in an equation that included both the main and interaction effects of emotion for the hotel data and then compared the amount of total explained variance accounted for by emotion in each equation. The amount of explained variance accounted for by the emotion variables (main and interaction effects) was higher in the SESat equation than in the cumulative satisfaction equation for the hotel setting $(8.6 \%>6.6 \%)$.

Also, Table 2 shows that the total explained variance is substantially higher for the service encounter satisfaction equation than for the cumulative satisfaction equation $(83 \%>35 \%)$ in the emotion group and only very slightly higher in the no-emotion group $(85 \%>84 \%)$. These results indicate that the effects of emotion have a greater impact on service encounter satisfaction than overall (cumulative) satisfaction. Thus, there is some evidence that emotion has relatively less influence on customers' cumulative satisfaction than on their transaction-based satisfaction. We might expect that the effect of emotion (relative to prior experiences) on cumulative satisfaction could be even less pronounced in actual situations where customers' prior experience with a service organization over time is more prominent in memory.

\section{Results Summary}

We found no effect of emotion in the restaurant setting. One possible explanation for the failure to find an effect of emotion in the restaurant data is that our experimental design does not control for heterogeneity in affect due to different focal restaurant "brands" (whereas the hotel data have only one focal brand). We found a significant and substantial effect of emotion in the hotel setting. It is surprising to discover that the effects of emotion may vary considerably across two different settings in the hospitality industry. If there is a main effect of emotion on satisfaction judgments, its effect size is too small to be detected in the industry subsamples. However, the combined industry sample results suggest that customers who respond to service failures with more (negative) emotion may be less satisfied with service failure/recovery encounters than those who respond with less (or no) emotion. In general, these findings provide a "conservative" estimate of the effect of emotion on customer satisfaction with service failure and recovery encounters. Customer reactions to service failures in credence services (e.g., financial, legal, medical services) may be even more emotion laden than their reactions to service failures in the hospitality industry.

In the hotel setting, it is also surprising to discover that emotion functions as a pure moderator (i.e., an interaction effect only) of the cognitive antecedents of satisfaction. The results for the hotel data show that customers who respond with more (negative) emotion will evaluate an organization's overall recovery effort more systematically than customers who respond with less (or no) emotion. In other words, recovery performance and other cognitive antecedents account for more of the explained variance in the satisfaction judgments of customers who respond with more negative emotion compared with the judgments of those who respond with less (or no) emotion. 
Our results also provide insights into how emotion moderates the effects of recovery performance and other cognitive antecedents on service encounter satisfaction in the hotel setting. Table 4 shows that distributive justice accounts for 3.6 percent of the explained variance in the satisfaction judgments for customers with no emotional response, whereas it accounts for 75.6 percent for customers with an emotional response. Interactional justice accounts for 62.4 percent of the explained variance in the satisfaction judgments for customers with no emotional response, whereas it accounts for only 4.8 percent for customers with a negative emotional response. Therefore, customers with (negative) emotional responses to service failures weigh distributive justice more heavily-and interactional justice less heavily - than customers with no emotional response. In other words, fairness in the way in which information is exchanged and outcomes communicated becomes much less important when the failure produces negative emotion. Instead, customers focus on the outcome itself (i.e., recovery attributes and distributive justice). Apparently, it simply is not possible to make customers feel better about a failure through interactional justice, that is, through appropriate courtesy, concern, effort, and so forth. Customers are focusing on distributive gains (e.g., discounts, vouchers, etc.), so recovery efforts must focus on improving the outcome from the customer's viewpoint.

There are two reasons to believe that the effects of emotional responses observed in this study will generalize to real-life service encounters. First, two features of our study ensure that the effects of emotion are not inadvertently inflated through a confounding with other factors. We measure customers' emotional responses with a conservative coding scheme based on verbal protocols. This feature ensures that emotional responses do not covary with other survey ratings measures, including satisfaction ratings, due to measurement artifacts. We also control for involvement levels (i.e., number of thoughts) and cognitive antecedents in modeling service encounter satisfaction. This feature ensures that emotional responses are not confounded with involvement and cognitive antecedents-which are likely to vary widely in real-life service encounters. The second reason for believing that these results will generalize to real-life service encounters is that experimentally generated scenarios are unlikely to stimulate the wide range of emotional responses that would typically be observed in customer service settings. These circumstances make it particularly challenging to detect the effects of emotional responses on satisfaction, yet we do find them in this study.

\section{MANAGERIAL IMPLICATIONS}

The research design used in this study overcomes some of the practical and ethical barriers to manipulating negative emotions related to service failure encounters. Therefore, our study yields some interesting findings related to the role of emotion and shows that failure to consider and/or measure customers' emotional responses could result in misleading predictions about satisfaction and/or incomplete understanding of customers' evaluations. Specifically, our results have important implications for how organizations should manage their transactions and relationships with customers, especially after a service failure has occurred. Prior research has focused on the cognitive antecedents of customer satisfaction to identify ways to improve service and customer satisfaction. This study focuses on emotions rather than cognition. Our results suggest that customers' emotional responses to poor service levels may partially account for lower satisfaction levels.

Dubé and Menon (1998) have argued that if customers express negative emotions and the service provider successfully decodes them, then the service provider can change his or her performance and create higher levels of service encounter satisfaction. They cite evidence from several studies that suggests that service providers have been able to successfully employ these strategies in specific consumption situations such as hospitalization and delayed airline flights (p. 133). This notion is consistent with prior research that has stressed how the social aspects of service encounters (personalization, friendliness, self-disclosure) are critical to customer satisfaction and loyalty (e.g., Goodwin and Gremler 1996). Thus, knowledge of the impact of emotions experienced by customers during service failure and recovery encounters can help managers to engineer the service delivery process to maximize satisfaction.

Managers can reengineer the service delivery process in three ways. First, service providers must be hired and trained for their ability to decode emotional cues. In other words, they must be able to recognize when customers are angry, disappointed, anxious, and so forth. Dubé and Menon (1998:139) have argued that customers express negative emotions using distinct patterns of facial, postural, vocal, and verbal cues corresponding to discrete negative emotions. If such cues are not evident, service providers must encourage customers to verbalize their emotions so they can be recognized.

Second, service providers must be trained to offer customized recovery efforts to customers who exhibit negative emotional cues. Since customers who exhibit (negative) emotional responses pay more attention to recovery efforts and weigh them more carefully, customized recovery efforts must include a variety of provider responses. However, recovery efforts should be especially targeted at improving customers' perceptions of service performance levels and distributive justice by restoring the customers' situation to its initial state (before failure). Since it is inevitably difficult to do this, the popular notion that service 
recovery requires "something extra" to create delight may well be true. For example, a hotel that does not have a reserved room available might have to go to considerable effort to create a lodging alternative that the customer considers equivalent to having the room he or she originally booked available immediately. Improvements to customers' perceptions of service performance levels and distributive justice target the key cognitive antecedents of customer satisfaction for customers with (negative) emotional responses. However, the service provider may also be able to bypass cognition and directly influence emotions. For example, Dubé and Menon (1998) have suggested that empathic reactions such as "mimicking" customers' displays of negative emotions may give the service provider an opportunity to guide the customer toward a satisfactory service outcome.

Third, managers should create service delivery processes that allow for customized recovery efforts directed at improving the emotional customers' situation on multiple dimensions. They should make an array of tools and resources available to service providers. Recall that, in our study, customers with (negative) emotional responses placed greater value on compensation than customers with no emotional response. This result is an important reminder that redressing service failures means more than smiles-it means delivery of core services. Thus, service employees must have a real ability to improve customers' situations.

In summary, this study suggests potential new ways for managers to increase satisfaction by improving their understanding of the complexity of customer emotions and the role of emotions in customers' responses to service failure and recovery encounters. Our results demonstrate the importance of providing managers with insights into how to (1) train personnel to identify and respond effectively to customer emotions caused by service failures, (2) enable staff to tailor service recovery efforts to "fit" the emotional state of the customer, and (3) empower frontline employees to alleviate negative emotions and diffuse customer anger.

\section{FUTURE RESEARCH}

Both of the studies described in this article were conducted in the hospitality industry. Therefore, more research is needed to examine the effects of emotions in different industry and study contexts. In addition, more research is required concerning the different categories of emotions and how they influence customers' satisfaction judgments. Our data showed that customers experienced different emotional responses after different types of service failures. Specifically, the incidence of anger, discontent, disappointment, self-pity, and anxiety differed significantly across the four failure types (outcome or process, high or low magnitude) in both the restaurant and hotel subsamples $(p<.01)$.

Unfortunately, the incidence of each type of emotional response is too small to allow us to model their influence on satisfaction judgments. However, an exploration of the effect of different types of emotional responses on satisfaction judgments is an interesting topic for future research. Some researchers have been successful in using scenarios to generate discrete emotional responses such as anger (Bagozzi et al. 1999:190) — this approach would make it possible to study specific types of emotional responses in depth.

\section{ACKNOWLEDGMENTS}

The authors gratefully acknowledge the financial support of the Marketing Science Institute.

\section{NOTES}

1. We conducted manipulation checks for failure severity, which showed that for both restaurants and hotels, low-magnitude failure conditions had significantly lower severity ratings than high-magnitude failure conditions. We also conducted mean difference tests on the manipulations checks for failure severity to ensure that there was no significant difference in severity based on failure type. The study results also show that customers responded differently (in terms of satisfaction) to outcome versus process failures and therefore were able to distinguish outcome and process dimensions.

2. We do not manipulate specific emotions or appraisal conditions. Bagozzi, Gopinath, and Nyer (1999) suggested that discrete emotions are likely when the study involves manipulations intended to produce specific appraisals or when naturally occurring events correspond to unique appraisal conditions. Our experimental design was intended to elicit failureprovoked emotions using common and realistic scenarios. Our intent was to measure, not manipulate, emotion in an unobtrusive way to avoid eliciting emotions that otherwise may not have existed. For this reason, we used verbal protocols, not direct measures, to capture customers' emotional responses.

3. On the basis of prior research, we created a negative emotion coding scheme as a form of exploratory analysis. Although we did not use the discrete categories in the estimation of our model, the results of this study seem to indicate that our approach to categorizing negative emotions may be a fruitful one. Also note that since the coding of presence versus absence of emotion was completely objective, interrater reliability measures are not necessary.

4. In the pooled data, the interaction effects of emotion on recovery efforts can partially or completely offset the negative main effect of emotion. When respondents in the emotion group are shown a "typical" recovery scenario, the magnitude of the moderating (positive) effect on recovery efforts is almost exactly equal to the main (negative) effect $(0.97>0.95)$. In other words, the net effect (main plus interaction effect) of emotion on satisfaction is virtually zero. When respondents in the emotion group are shown an "excellent" recovery scenario, the net effect of emotion on satisfaction becomes positive. In the pooled data, the interaction effect of emotion explains 13.7 percent of the variance in customers' service encounter satisfaction. In contrast, the main effect of emotion explains 1.5 percent of the variance. Interestingly, the results from the pooled data indicate that after controlling for the main effect of emotion, the interaction effect of (negative) emotion causes customers to evaluate 
a given recovery effort more favorably (ceteris paribus) that is, they derive higher satisfaction from recovery attributes.

5. In the hotel data, the $R^{2}$ of the equation describing customers who respond with emotion is slightly lower than the $R^{2}$ for the equation describing customers who respond with less emotion. Since we know that customers with an emotional response generate more thoughts-consistent with cognitive activity - this result suggests that our regression equation cannot capture some of the affective (as opposed to cognitive) factors that are being processed to form satisfaction judgments.

\section{REFERENCES}

Adams, J. Stacy. 1965. "Inequity in Social Exchange." In Advances in Experimental Social Psychology, Vol. 2. Ed. Leonard Berkowitz. New York: Academic Press, 267-299.

Alford, Bruce L. and Daniel Sherrell. 1996. "The Role of Affect in Consumer Satisfaction Judgments of Credence-Based Services.” Journal of Business Research 37:71-84.

Andreassen, Tor Wallin. 1999. "What Drives Customer Loyalty With Complaint Resolution?” Journal of Service Research 1 (4): 324-332.

- 2000. "Antecedents to Satisfaction With Service Recovery." European Journal of Marketing 34 (1/2): 156-175.

Bagozzi, Richard P., Mahesh Gopinath, and Prashanth U. Nyer. 1999. "The Role of Emotions in Marketing," Journal of the Academy of Marketing Science 27 (2): 184-206.

Baron, Reuben M. and David A. Kenny. 1986. "The Moderator-Mediator Variable Distinction in Social Psychological Research: Conceptual, Strategic, and Statistical Considerations." Journal of Personality and Social Psychology 51 (6): 1173-1182.

Batra, Rajeev and Morris Holbrook. 1990. "Developing a Typology of Affective Responses to Advertising." Psychology \& Marketing 7 (Spring): 11-25.

Bearden, William O. and Richard L. Oliver. 1985. "The Role of Public and Private Complaining in Satisfaction With Problem Resolution." Journal of Consumer Affairs 19 (2): 222-240.

Berry, Leonard L. and A. Parasuraman. 1991. Marketing Services: Competing Through Quality. New York: Free Press.

Bies, Robert J. and Joseph S. Moag. 1986. "Interactional Justice: Communication Criteria of Fairness." In Research on Negotiation in Organizations, Vol. 1. Eds. Roy J. Lewicki, Blair H. Sheppard, and Max H. Bazerman. Greenwich, CT: JAI, 43-55.

and Debra L. Shapiro. 1987. "Interactional Fairness Judgments: The Influence of Causal Accounts." Social Justice Research 1 (2): 199-218.

Bitner, Mary Jo. 1990. "Evaluating Service Encounters: The Effects of Physical Surroundings and Employee Responses," Journal of Marketing 54 (April): 69-82.

— Bernard H. Booms, and Mary Stanfield Tetreault. 1990. "The Service Encounter: Diagnosing Favorable and Unfavorable Incidents." Journal of Marketing 54 (January): 71-84.

Bless, Herbert, Gerd Bohner, Norbert Schwarz, and Fritz Strack. 1990. "Mood and Persuasion: A Cognitive Response Analysis." Personality and Social Psychology Bulletin 16 (2): 331-345.

— Rabe, and Marcus Welk. 1996. "Mood and the Use of Scripts: Does a Happy Mood Really Lead to Mindlessness?" Journal of Personality and Social Psychology 71 (4): 665-679.

Blodgett, Jeffrey G., Donald H. Granbois, and Rockney G. Walters. 1993. "The Effects of Perceived Justice on Complainants' Negative Word-of-Mouth Behavior and Repatronage Intentions." Journal of Retailing 69 (4): 399-428.

— Donna J. Hill, and Stephen S. Tax. 1997. "The Effects of Distributive, Procedural, and Interactional Justice on Postcomplaint Behavior." Journal of Retailing 73 (2): 185-210.

Bolton, Ruth N. 1998. "A Dynamic Model of the Customer's Relationship With a Continuous Service Provider: The Role of Satisfaction." Marketing Science 17 (1): 45-65.
Boulding, William, Ajay Kalra, and Richard Staelin. 1995. "The Quality Double Whammy: The Rich Stay Rich and the Poor Stay Poor." Working Paper. Duke University.

Chow, G. C. 1960. "Test of Equality Between Sets of Coefficients in Two Linear Regressions.” Econometrika 28 (July): 591-605.

Churchill, Gilbert A., Jr. and Carol Surprenant. 1982. "An Investigation Into the Determinants of Customer Satisfaction." Journal of Marketing Research 19 (4): 491-504.

Clemmer, Elizabeth C. and Benjamin Schneider. 1993. "Managing Customer Dissatisfaction With Waiting: Applying Social-Psychological Theory in a Service Setting." In Advances in Services Marketing and Management, Vol. 2. Eds. Teresa A. Swartz, David E. Bowen, and Stephen W. Brown. Greenwich, CT: JAI, 213-229.

Cohen, Joel B. and Charles S. Areni. 1991. "Affect and Consumer Behavior." In Handbook of Consumer Behavior. Eds. Thomas S. Robertson and Harold Kassarjian. Englewood Cliffs, NJ: Prentice Hall, 188-240.

Collins, M. and G. Kalton. 1980. "Coding Verbatim Answers to Open Questions." Journal of the Market Research Society 22:239-247.

Deutsch, Morton. 1975. "Equity, Equality, and Need: What Determines Which Value Will Be Used as the Basis of Distributive Justice?" Journal of Social Issues 31 (3): 137-149.

Dubé, Laurette and M. Maute. 1996. "The Antecedents of Brand Switching, Brand Loyalty and Verbal Responses to Service Failure." In Advances in Services Marketing and Management: Research and Practice, Vol. 5. Eds. T. Swartz, D. Bowen, and S. Brown. Greenwich, CT: JAI, 127-151.

_ and Kalyani Menon. 1998. "Why Would Certain Types of In-Process Negative Emotions Increase Post-Purchase Consumer Satisfaction With Services?" Advances in Services Marketing and Management 7:131-158.

_ and Michael S. Morgan. 1996. "Trend Effects and Gender Differences in Retrospective Judgments of Consumption Experiences." Journal of Consumer Research 23 (September): 156-162.

Edell, Julie A. and Marian Chapman Burke. 1987. "The Power of Feelings in Understanding Advertising Effects." Journal of Consumer Research 14 (December): 421-433.

Fiebig, Greg V. and Michael W. Kramer. 1998. "A Framework for the Study of Emotions in Organizational Contexts." Management Communication Quarterly 11 (4): 536-572.

Fiedler, Klaus. 1990. "Mood-Dependent Selectivity in Social Cognition." In European Review of Social Psychology, Vol. 1. Eds. Wolfgang Stroebe and Miles Hewstone. New York: John Wiley, 1-32.

Folkes, Valerie S., Susan Koletsky, and John L. Graham. 1987. "A Field Study of Causal Inferences and Consumer Reaction: The View From the Airport." Journal of Consumer Research 13 (March): 534-539.

Forgas, Joseph P. 1994. "The Role of Emotion in Social Judgments: An Introductory Review and an Affect Infusion Model (AIM)." European Journal of Social Psychology 24:1-24.

- 1995. "Mood and Judgment: The Affect Infusion Model (AIM)." Psychological Bulletin 117 (1): 39-66.

Frijda, Nico H. 1986. The Emotions. Cambridge, UK: Cambridge University Press.

Gilly, Mary C. and Betsy D. Gelb. 1982. "Post-Purchase Consumer Processes and the Complaining Consumer." Journal of Consumer Research 9 (December): 323-328.

Glesjer, H. 1969. "A New Test for Heteroscedasticity." Journal of the American Statistical Association 64:316-323.

Goodwin, Cathy and Dwayne D. Gremler. 1996. "Friendship Over the Counter: How Social Aspects of Service Encounters Influence Consumer Service Loyalty." In Advances in Services Marketing and Management, Vol. 5. Eds. Teresa A. Swartz, David E. Bowen, and Stephen W. Brown. Greenwich, CT: JAI, 247-282.

_ and Ivan Ross. 1992. "Consumer Responses to Service Failures: Influences of Procedural and Interactional Fairness Perceptions." Journal of Business Research 25:149-163.

Greene, William H. 1993. Econometric Analysis. New York: Macmillan.

Hoffman, K. Douglas, Scott W. Kelley, and Holly M. Rotalsky. 1995. "Tracking Service Failures and Employee Recovery Efforts." Journal of Services Marketing 9 (2): 49-61. 
Hui, Michael K. and David K. Tse. 1996. "What to Tell Consumers in Waits of Different Lengths: An Integrative Model of Service Evaluation." Journal of Marketing 60 (April): 81-90.

Irwin, Julie R. and Gary H. McClelland. 2001. "Misleading Heuristics and Moderated Multiple Regression Models." Journal of Marketing Research 38 (1): 100-109.

Isen, Alice M. 1997. "Positive Affect and Decision Making." In Research on Judgment and Decision Making: Currents, Connections, Controversies. Eds. William M. Goldstein and Robin M. Hogarth. Cambridge, UK: Cambridge University Press, 509-534.

Isen, Alice M. 1987. "Positive Affect, Cognitive Processes, and Socia Behavior." In Advances in Experimental Social Psychology, Vol. 20. Ed. Leonard Berkowitz. New York: Academic Press, 203-253.

- Thomas E. Shalker, Margaret Clark, and Lynn Karp. 1978. "Affect, Accessibility of Material in Memory, and Behavior: A Cognitive Loop?" Journal of Personality and Social Psychology 36 (1): 1-12.

Izard, Carroll E. 1977. Human Emotions. New York: Plenum.

Jedidi, Kamel, Harsharanjeet S. Jagpal, and Wayne S. DeSarbo. 1997. "Finite-Mixture Structural Equation Models for Response-Based Segmentation and Unobserved Heterogeneity." Marketing Science 16 (1): 39-59.

Johnston, J. 1972. Econometric Methods. New York: McGraw-Hill.

Keaveney, Susan M. 1995. "Customer Switching Behavior in Service Industries: An Exploratory Study.” Journal of Marketing 59 (2): 71-82.

Lazarus, Richard S. 1991. Emotion and Adaptation. New York: Oxford University Press.

Leventhal, Gerald S. 1980. "What Should Be Done With Equity Theory? New Approaches to the Study of Fairness in Social Relationships." In Social Exchange: Advances in Theory and Research. Eds. Kenneth J. Gergen, Martin S. Greenberg, and Richard H. Willis. New York: Plenum, 27-55.

Lind, E. Allen and Tom R. Tyler. 1988. The Social Psychology of Procedural Justice. New York: Plenum.

Mackie, Diane M. and Leila T. Worth. 1989. "Processing Deficits and the Mediation of Positive Affect in Persuasion.” Journal of Personality and Social Psychology 57 (1): 27-40.

Mano, Haim and Richard L. Oliver. 1993. "Assessing the Dimensionality and Structure of Consumption Experience: Evaluation, Feeling, and Satisfaction." Journal of Consumer Research 20:451-466.

Maute, Manfred F. and William R. Forrester, Jr. 1993. "The Structure and Determinants of Consumer Complaint Intentions and Behavior." Journal of Economic Psychology 14:219-247.

Mehrabian, Albert and James A. Russell. 1974. An Approach to Environmental Psychology. Cambridge: MIT Press.

Morton-Williams, J. and P. Young. 1987. "Obtaining the Survey Interview: An Analysis of Tape Recorded Doorstep Introductions." Journal of the Market Research Society 29:35-54.

Neter, John and William Wasserman. 1974. Applied Linear Statistical Models: Regression, Analysis of Variance, and Experimental Designs. Homewood, IL: Irwin.

Oliver, Richard L. 1980. "A Cognitive Model of the Antecedents and Consequences of Satisfaction Decisions." Journal of Marketing Research 42 (4): 460-469.

1993. "Cognitive, Affective and Attribute Bases of the Satisfaction Response." Journal of Consumer Research 20 (December): 418-430.

. 1997. "Emotional Expression in the Satisfaction Response." In Satisfaction: A Behavioral Perspective on the Consumer. Boston: Irwin, 291-325.

_ and Wayne S. DeSarbo. 1988. "Response Determinants in Satisfaction Judgments." Journal of Consumer Research 14 (March): 495-507.

and John E. Swan. 1989a. "Consumer Perceptions of Interpersonal Equity and Satisfaction in Transactions: A Field Survey Approach." Journal of Marketing 53 (April): 21-35.

_ and John E. Swan. 1989b. "Equity and Disconfirmation Perceptions as Influences on Merchant and Product Satisfaction." Journal of Consumer Research 16 (December): 372-383.

Plutchik, Robert. 1980. Emotion: A Psychoevolutionary Synthesis. New York: Harper \& Row.

Richins, Marsha L. 1983. "Negative Word-of-Mouth by Dissatisfied Consumers: A Pilot Study." Journal of Marketing 47 (Winter): 68-78.
1997 "Measuring Emotions in the Consumption Experience." Journal of Consumer Research 24 (September): 127-146.

Roseman, Ira J. 1991. "Appraisal Determinants of Discrete Emotions." Cognition and Emotion 5:161-200.

Schwarz, Norbert. 1990. "Feelings as Information: Informational and Motivational Functions of Affective States." In Handbook of Motivation and Cognition: Foundations of Social Behavior, Vol. 2. Eds. R. M. Sorrentino and E. T. Higgins. New York: Guilford, 527-561. and Herbert Bless. 1991. "Happy and Mindless, But Sad and Smart? The Impact of Affective States on Analytic Reasoning." In Emotion and Social Judgments. Ed. Joseph P. Forgas. London: Pergamon, 55-71.

- and Gerald Clore. 1983. "Mood, Misattribution, and Judgments of Well-Being: Informative and Directive Functions of Affective States." Journal of Personality and Social Psychology 45 (3): 513-523.

Sharma, Subhash, Richard M. Durand, and Oded Gur-Arie. 1981: "Identification and Analysis of Moderator Variables." Journal of Marketing Research 18 (August): 291-300.

Shiv, Baba and Alexander Fedorikhin. 1999. "Heart and Mind in Conflict: The Interplay of Affect and Cognition in Consumer Decision Making." Journal of Consumer Research 26 (December): 278-292.

Singh, Jagdip. 1990. "Voice, Exit, and Negative Word-of-Mouth Behaviors: An Investigation Across Three Service Categories." Journal of the Academy of Marketing Science 18 (1): 1-15.

Smith, Amy K., Ruth N. Bolton, and Janet Wagner. 1999. "A Model of Customer Satisfaction With Service Encounters Involving Failure and Recovery." Journal of Marketing Research 36 (3): 356-372.

Sparks, Beverley A. and Victor J. Callan. 1996. "Service Breakdowns and Service Evaluations: The Role of Customer Attributions." Journal of Hospitality \& Leisure Marketing 4 (2): 3-24.

Srull, Thomas K. 1983. "Affect and Memory: The Impact of Affective Reactions in Advertising on the Representation of Product Information in Memory." In Advances in Consumer Research, Vol. 10. Eds. Richard P. Bagozzi and Alice Tybout. Ann Arbor, MI: Association for Consumer Research, 520-525.

Srull, Thomas K. 1984. "The Effects of Subjective Affective States on Memory and Judgment." In Advances in Consumer Research, Vol. 11. Ed. Thomas C. Kinnear. Provo, UT: Association for Consumer Research, 530-533.

Tax, Stephen Saul, Stephen W. Brown, and Murali Chandrashekaran. 1998. "Customer Evaluations of Service Complaint Experiences: Implications for Relationship Marketing." Journal of Marketing 62 (April): 60-76.

and Murali Chandrashekaran. 1992. "Consumer Decision Making Following a Failed Service Encounter: A Pilot Study.” Journal of Consumer Satisfaction, Dissatisfaction and Complaining Behavior 5:55-68.

Taylor, Shirley. 1994. "Waiting for Service: The Relationship Between Delays and Evaluations of Service." Journal of Marketing 58 (April): 56-69.

Thibaut, John and Laurens Walker. 1975. Procedural Justice: A Psychological Analysis. Hillsdale, NJ: Lawrence Erlbaum.

Weber, R. P. 1985. Basic Content Analysis. Sage University Series on Quantitative Applications in the Social Sciences. Beverly Hills, CA, and London: Sage, 7-49.

Westbrook, Robert A. 1987. "Product/Consumption-Based Affective Responses and Postpurchase Processes." Journal of Marketing Research 24 (August): 258-270.

and Richard L. Oliver. 1991. "The Dimensionality of Consumption Emotion Patterns and Consumer Satisfaction." Journal of Consumer Research 18 (June): 84-91.

Wirtz, Jochen, and John E. G. Bateson. 1999. "Consumer Satisfaction With Services: Integrating the Environment Perspective in Services Marketing Into the Traditional Disconfirmation Paradigm." Journal of Business Research 44:55-66.

Yates, Frank J. 1990. Judgment and Decision Making. Englewood Cliffs, NJ: Prentice Hall.

Zeithaml, Valarie A., Leonard L. Berry, and A. Parasuraman. 1993. "The Nature and Determinants of Customer Expectations of Service." Journal of the Academy of Marketing Science 21 (1): 1-12. 


\section{ABOUT THE AUTHORS}

Amy K. Smith (Ph.D., University of Maryland) is currently an assistant professor of marketing at George Washington University. Her research focuses on customer assessments of services, customer satisfaction and retention, customer service, service failure and recovery, and customer-service provider relationships in both business-to-consumer and business-to-business markets. Her research has been published in the Journal of Marketing Research and the Journal of Service Research.
Ruth N. Bolton is currently a Ruby K. Powell Professor of Marketing in the Michael F. Price College of Business at the University of Oklahoma. Her research focuses on how organizations can grow the value of their customer base through customer service and support. Her research has been published in the Journal of Retailing, the Journal of Marketing, Marketing Science, Marketing Letters, the Journal of Marketing Research, and the Journal of Service Research. 